\title{
Over de grens in beeld
}

De oproep in H\&W om foto's en bijdragen aan te leveren rondom het thema 'Over de grens' leverde zeer divers materiaal op. Het thema raakt aan veel facetten van het huisartsenvak, zo blijkt. Aan landsgrenzen, vakgrenzen, persoonlijke grenzen en migratiegrenzen. Daarbovenop kwam nog de uitbraak van COVID-19, waardoor het woord 'grens' een heel andere lading kreeg. De uitgebreide versie van deze reportage is te zien op onze website.
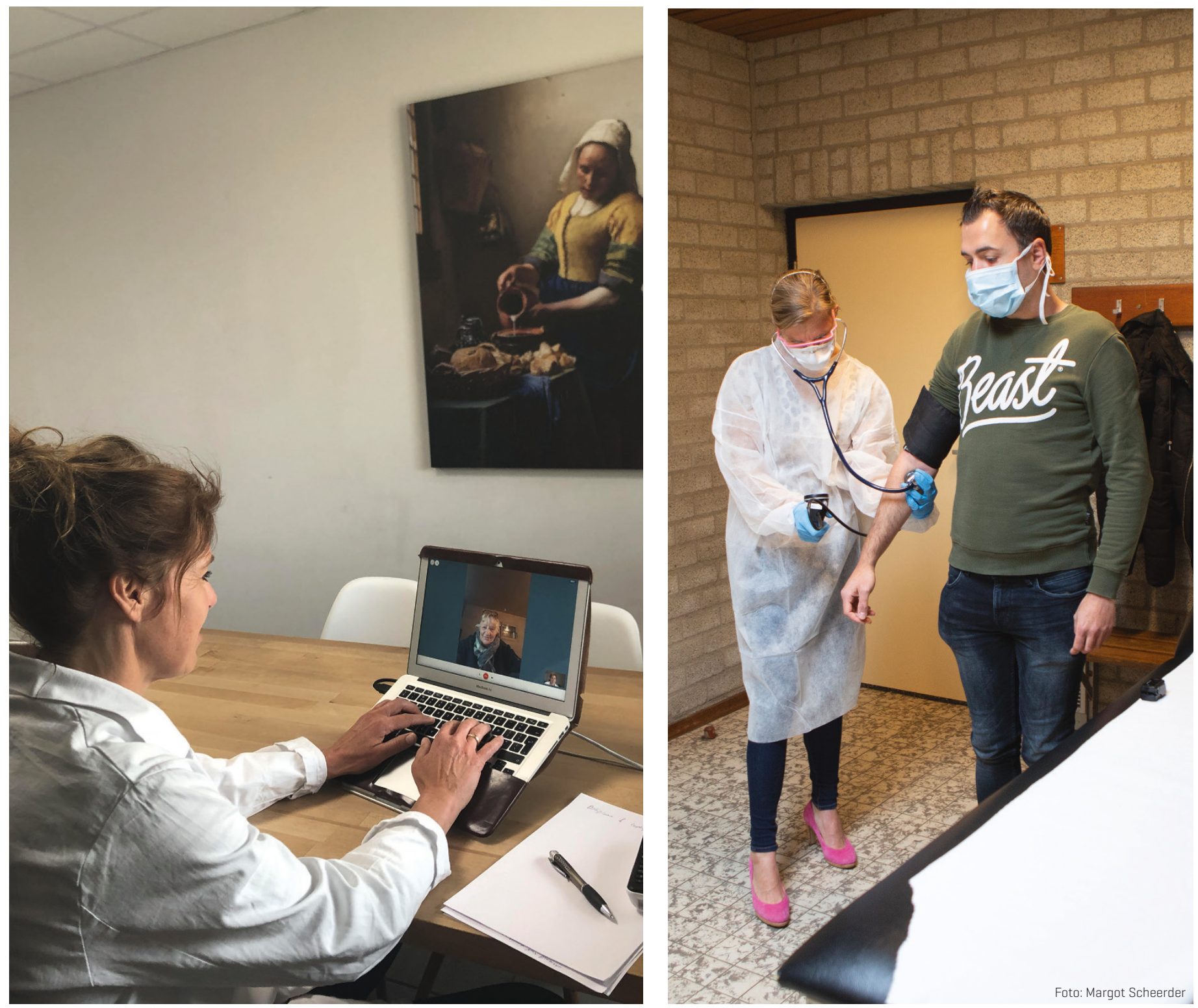

COVID-19 heeft wereldwijd veel impact op de gezondheidszorg en het werk van huisartsen. 4 De in Frankrijk werkende Annet Sollie videobelt met een patiënt. Dit gaat bij de meeste patiënten zo. Spreekuur gebeurt in witte doktersjas en met beschermende middelen. Margriet de Beus meet tijdens haar 'coronadienst' in een Brabantse sporthal in beschermende kleding de bloeddruk bij een patiënt. Beide foto's zijn begin april gemaakt. 


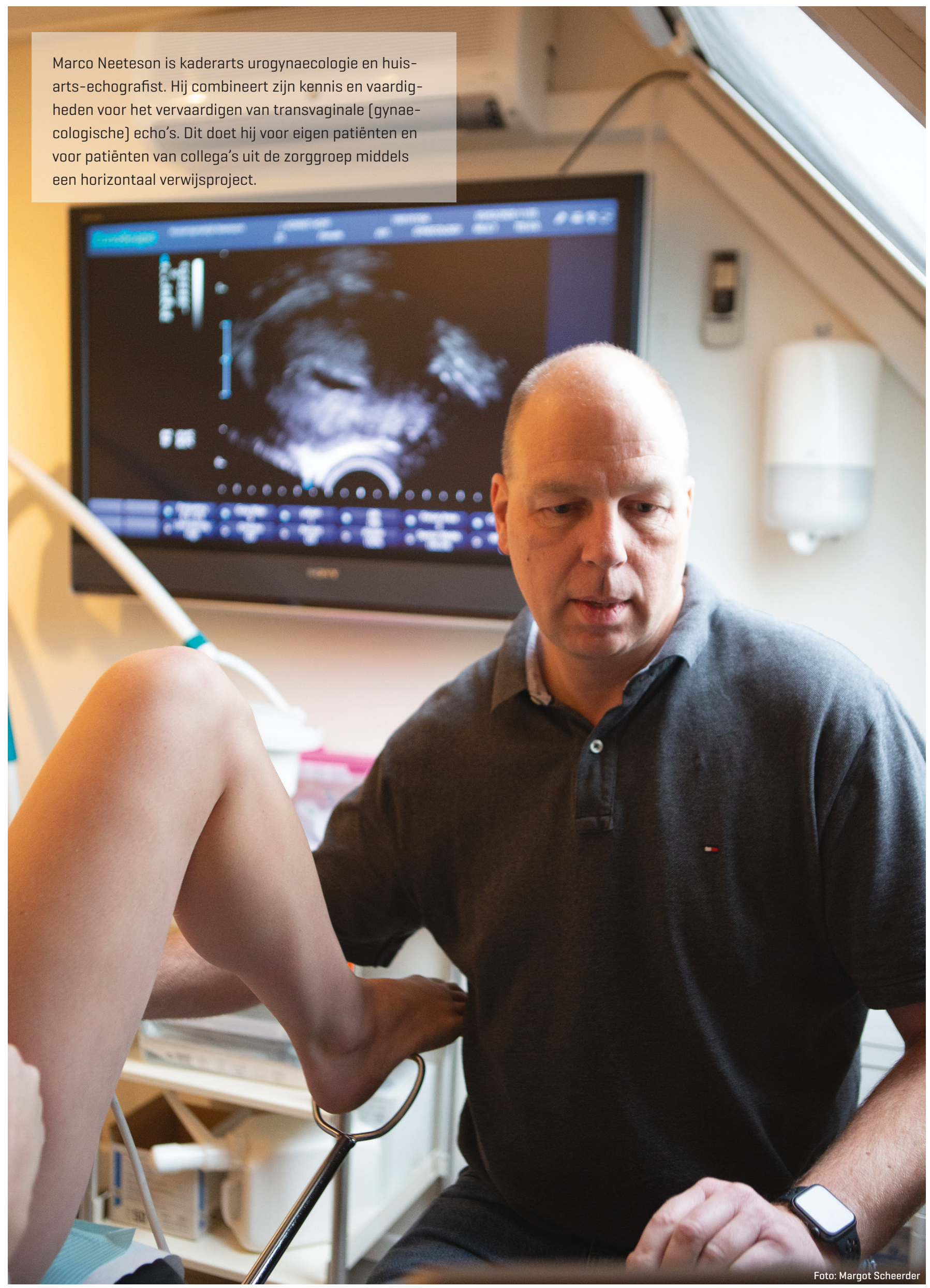


Begin januari ging huisarts Peter van Liere als scheepsarts aan boord van een expeditiecruiseboot, die hem naar Antarctica zou brengen. Hiervoor moet de Drake Passage overgestoken worden en bij het passeren van de denkbeeldige 60e zuidelijke breedtegraad bereik je volgens internationale afspraken Antarctica. Tijdens de cruise had hij de medische zorg over 160 passagiers en 70 bemanningsleden. De wetenschap dat medische voorzieningen naar westerse maatstaven 1000 kilometer verwijderd zijn en dat de afstand voor een heli-evacuatie te ver is, maakte het een bijzondere uitdaging.

$\boldsymbol{\nabla}$ In Nepal zorgen ernstige verzakkingen voor groot leed. De Stichting Vrouwen voor Vrouwen organiseert twee keer per jaar een gyno-camp. Nederlandse huisartsen gaan dan samen met Nepalese artsen en verpleegkundigen op pad om vrouwen gynaecologisch te onderzoeken. Ook worden Nepalese gynaecologen getraind in prolapsoperaties. De stichting betaalt de operatiekosten. Health workers krijgen onderwijs en leren hoe ze vrouwen moeten onderzoeken. Ook leren ze hoe ze bij een verzakking of fors urineverlies een geschikt pessarium kunnen plaatsen. Sandra Bijl stuurde deze foto van Nepalese vrouwen die voorlichting krijgen over baarmoederverzakkingen.

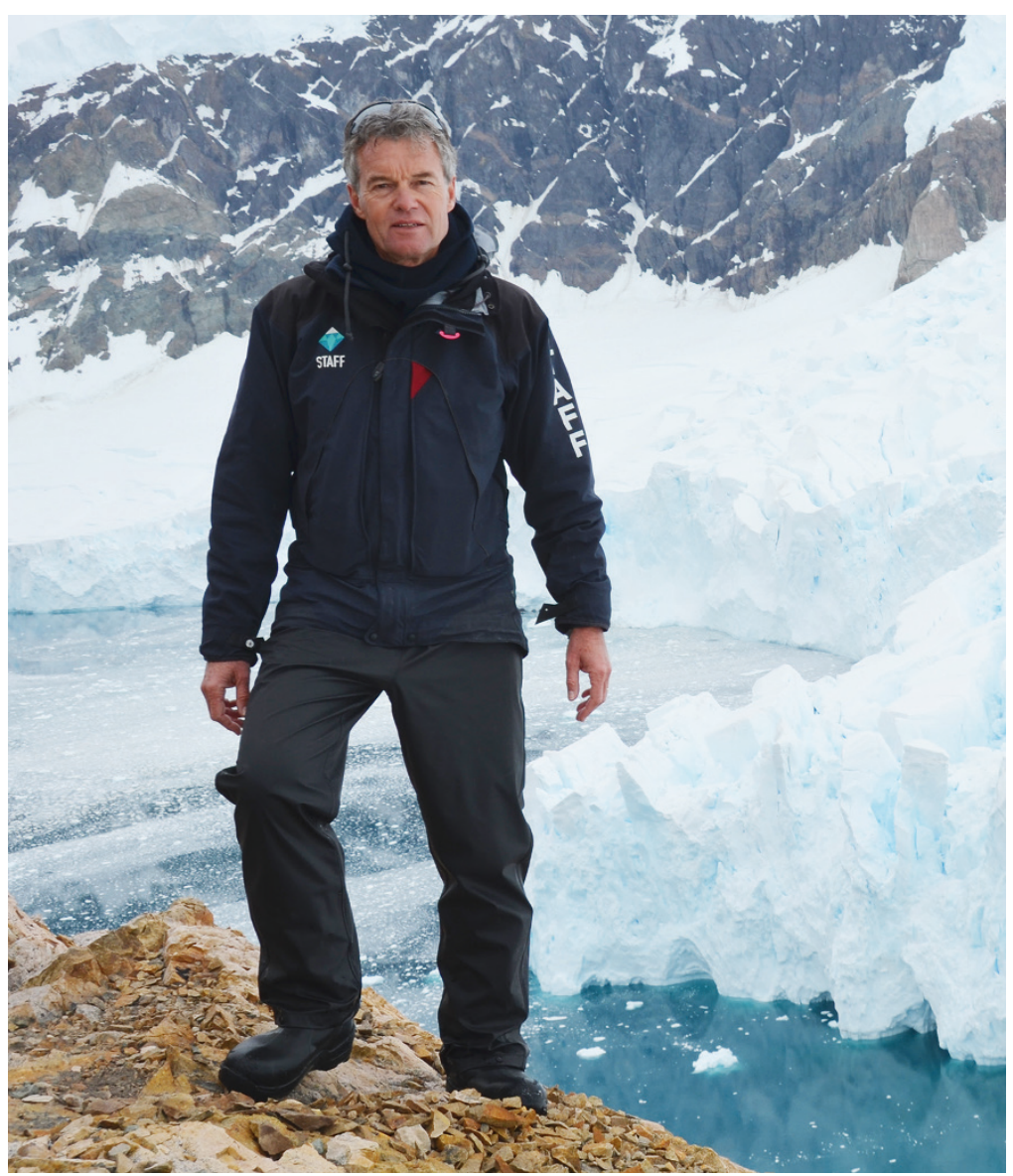

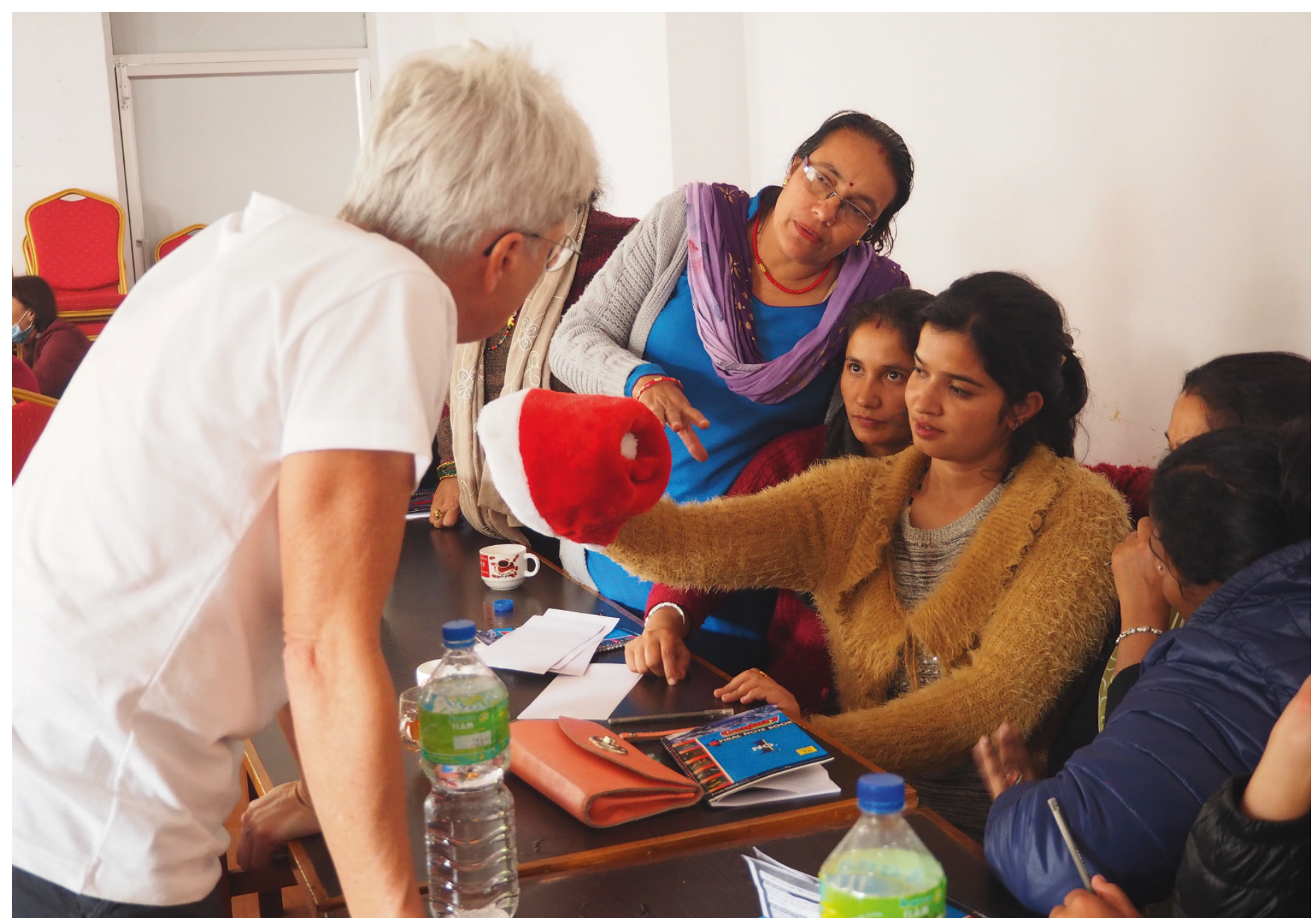




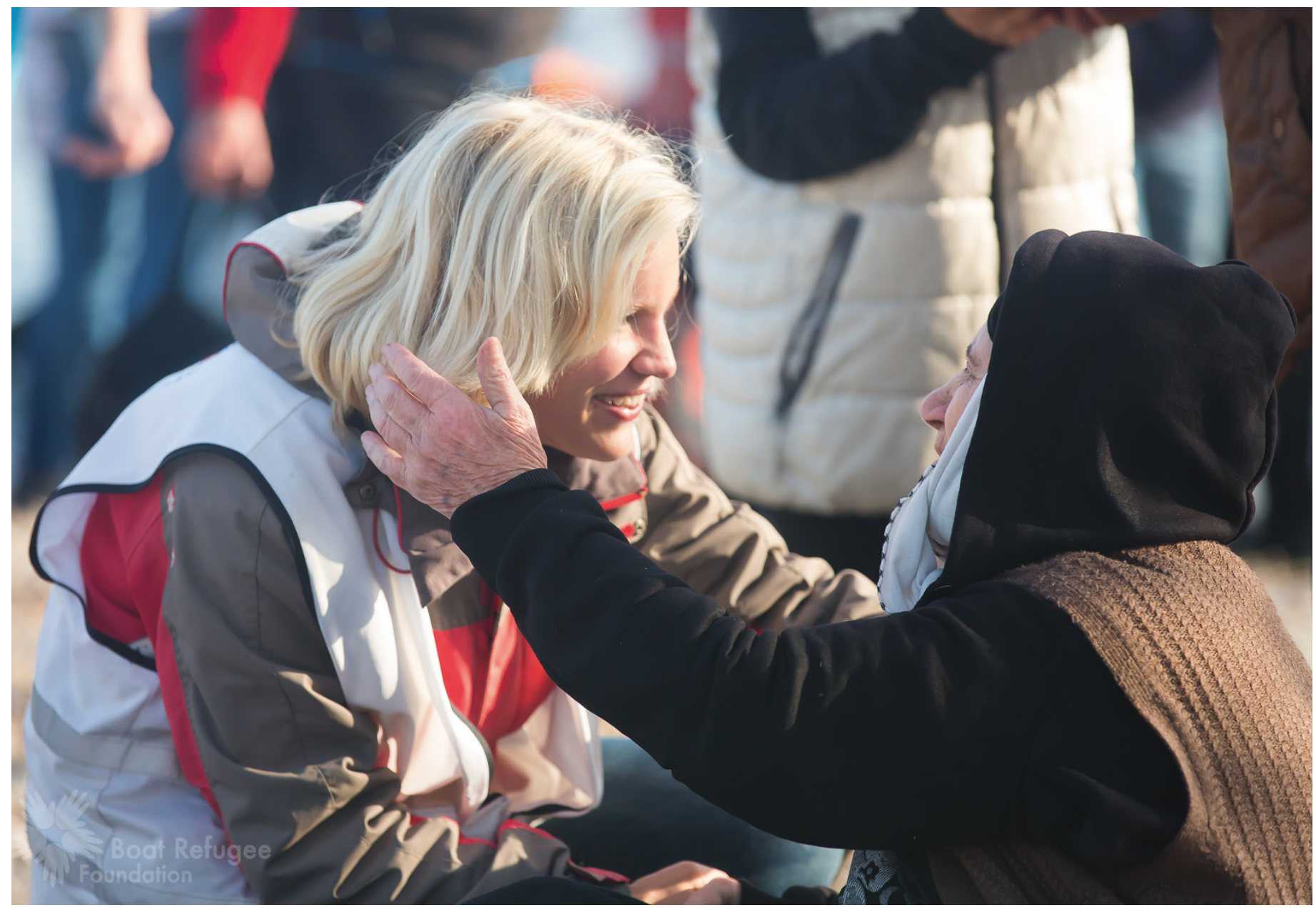

Moria op Lesbos is het grootste vluchtelingenkamp van Europa. Huisartsen Anja van Kempen, Marike Ooms en Anke Steerneman werkten daar. "Alles in Moria is over de grens", schrijft Anja. "Mensonwaardig, indrukwekkend, ontroerend, machteloosheid en toch voel je je als huisarts heel nuttig en past het werken daar bij je competenties." Marike werkte ook op Lesbos en daarnaast in een asielzoekerscentrum. "Dan leer je hoe belangrijk grenzen, paspoorten en nationaliteiten zijn. Grenzen kunnen van levensbelang zijn. Als Nederlander zijn we ons daar meestal niet van bewust." [Foto's: Stichting Bootvluchteling]
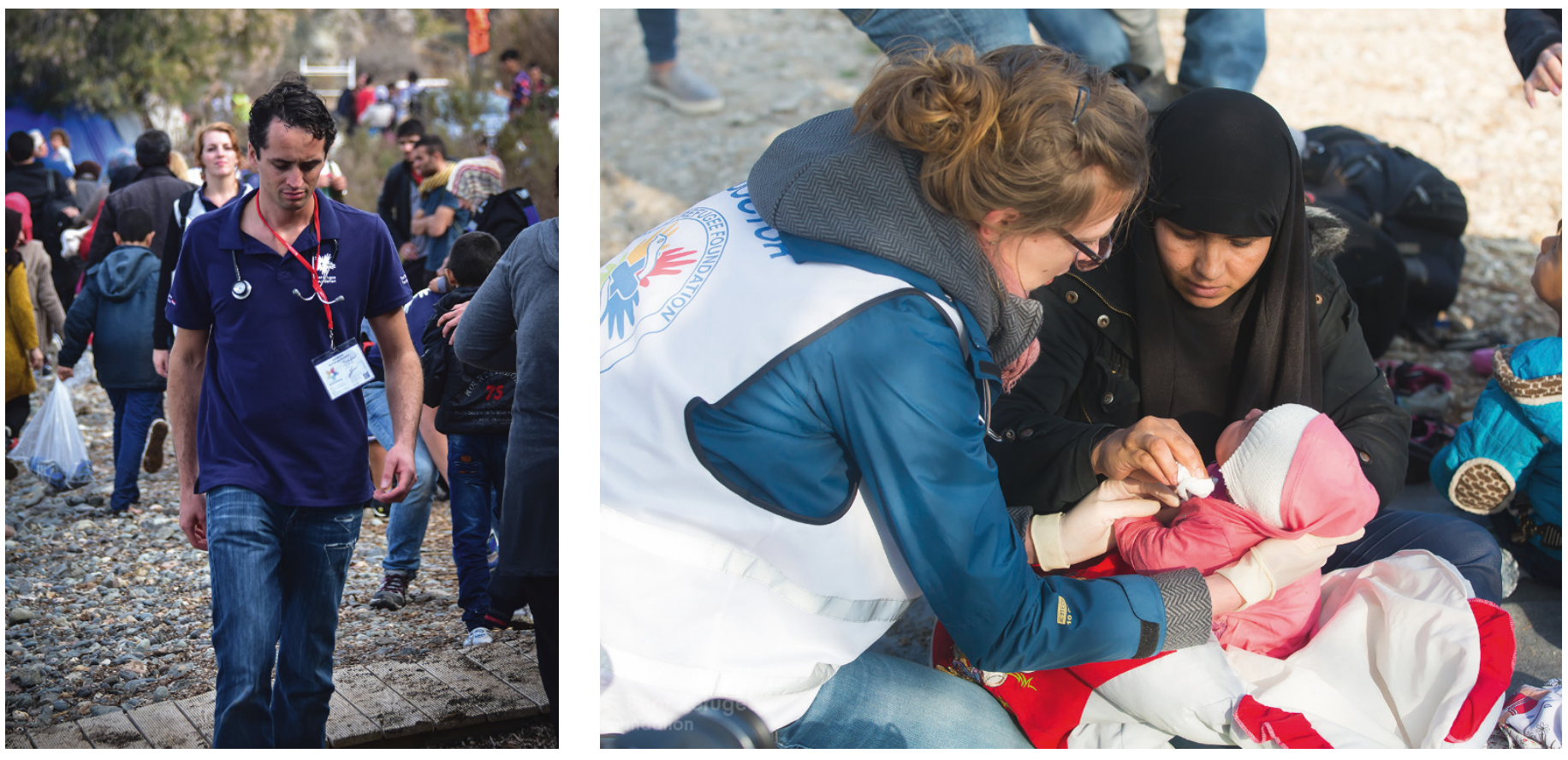